\title{
Effect of flower age on honey bee behaviour when rewards are kept constant.
}

\author{
Victoria J MacPhail*, Peter G Kevan, and Colleen Fuss. \\ Department of Environmental Biology, University of Guelph, Guelph, Ontario NI G 2WI, Canada.
}

Received 3 May 2007, accepted subject to revision, 29 May 2007, accepted for publication, 22 July 2007.

"Corresponding author: Email: vmacphai@uoguelph.ca

Keywords: Rosa virginiana, Apis mellifera, pollen, flower age, floral rewards, flower visitation, choice table, foraging behaviour

\section{Introduction}

Wild roses (Rosa spp.) have open, bowl-shaped flowers that are accessible to many insects (Kevan et al. 1990). The flowers of all rose species, except $R$. setigera, are hermaphroditic, and are generally devoid of nectar (Kevan et al. 1990; Kemp, 1994). They produce abundant pollen as reward for potential pollinators (Kevan et al. 1990). The odour of the pollen differs from the overall floral scent, leading bees at close range to the pollen (Dobson, 1991). However, flower colour also attracts bees, often from greater distances than olfactory cues (Dobson, 1991; Proctor et al. 1996). As the flower ages, rose petals fade and their anthers brown (Kemp, 1994). We investigated the effect of rose flower age on the behaviour of honey bees (Apis mellifera) when the pollen reward is kept constant.

The experiment used Rosa virginiana flowers at Rice Point, Prince Edward Island (N 46.I4 I 08 W 63.27249), during days with similar, sunny, weather conditions. There was an apiary adjacent to the site, with numerous honey bees present. A choice table was placed within a large patch of roses. It consisted of four arms (arrays), balanced on a stake driven into the ground, whose ends supported a small platform with five vials (four forming a square, and a fifth in the center), into which combinations of first or second day flowers were placed after cutting (Kevan et al. 1990). The treatments included I) five first day flowers, 2) five second day, 3) one first day (in center) and four second day, and 4) four first day and one second day (in center). Each vial was numbered, and contained water to prevent flower wilting. Flowers at the late-pink bud stage were selected, and then marked as to distinguish the day that they opened. First day flowers opened on the same day as the observations took place, while second day flowers opened on the previous day. All experimental flowers were covered by mesh bags before opening and between observation periods, to prevent insects from removing pollen, thereby keeping reward levels constant between the two ages.

Ten minute observations were conducted on the 15,30, and 45 minute mark hourly between $0915 \mathrm{~h}$ and I430h on 27,30 and 31 July 2004. Only one bee was observed at a time, and the number of approach-only, hover-only, and landing visits to individual flowers (flower ages) and arrays (flower combinations) were counted, and the foraging duration recorded. After it left the table, another bee would be followed. The choice table was rotated I/4 turn after each observation period so as to avoid positional effects of the arrays in relation to the site. All statistical analyses used SPSS v. I 4.0 for Windows (SPSS Inc., Chicago, Illinois), with a type I error rate of 0.05 . Chi-square tests were used to determine if the number of observations differed among insect behaviours. Differences in foraging times were investigated by ANOVA.

A combined total of 2693 visits (approach-only, hover-only, and landings) to individual flowers, made by 415 honey bees, were recorded over three days (Table 1). The number of approach-only visits did not differ significantly between first and second day flowers $\left(X^{2}=1.021, d f=1, p=0.312\right)$ or among arrays of flower age combinations $\left(X^{2}=3.318, d f=3, p=0.345\right)$. The number of hover-only visits differed significantly between individual flower ages $\left(X^{2}=9.284\right.$, $d f=I, p=0.002$ ), with second day flowers receiving more hover-only visits than first day ones. However, the number of hover-only visits did not differ significantly between the arrays of flower age combinations ( $X^{2}=3.099, \mathrm{df}=3, p=0.377$ ).

The number of landing visits to individual first day flowers differed significantly from the number of landing visits to second day flowers $\left(X^{2}=66.8 \mid 4, d f=1, p<0.001\right)$. There were also significant differences in the number of visits to different arrays $\left(X^{2}=51.052, \mathrm{df}=3\right.$, $p<0.00$ I); arrays of first day flowers received more landing visits than those of second day flowers, and the total number of landings on an array generally increased as the number of first day flowers in an array increased. For landing visits, excluding two where no times were recorded, no significant differences were found in foraging times between the individual flower ages $(F=0.626, d f=1,1860, p=0.429)$ or age combinations ( $F=0.7 \mathrm{I} \mathrm{I}, \mathrm{df}=3,1860, p=0.545)$, with a mean time of $3.38 \pm$ s.e. 0.073 s/visit $(n=\mid 864)$.

Individual flower age had no effect on the number of approachonly visits, and flower age combination had no effect on the number of approach-only and hover-only visits, but in almost all other cases, first day flowers, considered alone or in mixed groups, were preferentially visited. Kevan et al. (1990) and Kemp (1994) also found that honey bees were more attracted to, and spent more time foraging on, arrays combining mostly first day $R$. setigera flowers versus mostly second day flowers. Dobson (1991) found that 
approximately $85 \%$ of approaches by bumble bees to first day $R$. rugosa flowers resulted in landings and foraging, while the remaining I5\% of approaches resulted in flower inspections only. This is similar to the $75 \%$ of landing visits and $16 \%$ of hover-only visits to first day flowers we observed.

In many flowers, a colour change occurs along with a decrease in pollen and / or nectar rewards (Proctor et al. 1996). Bees are often attracted, and remain constant, to particular colours if rewards are available, and may avoid those that typically do not contain rewards (Menzel and Erber, 1978). They may also inspect flowers by hovering in front of them, as observed for roses by Dobson (1991) and Kemp (1994). Differences in the appearance of first and second day flowers were noted, with older flowers having paler petals and darker anthers. This may explain why second day flowers had more approach- and hover-only visits, and fewer landing visits, than did first day flowers. However, because the flowers used had been bagged, the amount of pollen present was consistent between ages. Therefore, although the petal colour may have changed, bees could have cued into the pollen odour, and upon landing, spend similar times foraging.

In summary, first day R. virginiana flowers were preferentially visited by honey bees over second day flowers, possibly because of their greater visual attractiveness. Future studies should investigate differences between bagged flowers with plentiful pollen and unbagged flowers with less pollen under natural conditions.

Table I. Total number of approach-only, hover-only, and landing visits made by 4 I 5 honey bees to individual first and second day flowers (upper portion of the table) and to arrays of flower age combinations (lower portion of table) of Rosa virginiana on Prince Edward Island, summed over three days of observations. Ten minute observations were carried out on the 15, 30, and 45 minute mark of every hour from $0915 \mathrm{~h}$ until $1430 \mathrm{~h}$ on 27, 30, and 31 July 2004. Asterisks (* for flower ages, ** for flower age combinations) indicate that the number of observed visits to each flower age or combination differed significantly from expected (equal numbers of visits) $\left(X^{2}\right.$ test, $\left.p<0.05\right)$.

\begin{tabular}{|c|c|c|c|c|}
\hline $\begin{array}{l}\text { Flower age or } \\
\text { combination }\end{array}$ & $\begin{array}{l}\text { \# of approach- } \\
\text { only visits }\end{array}$ & $\begin{array}{l}\text { \# of hover-only } \\
\text { visits }\end{array}$ & \# of landing visits & Total \\
\hline first day & 133 & $236^{*}$ & $1109 *$ & 1478 \\
\hline second day & 150 & $307 *$ & $756^{*}$ & 1213 \\
\hline Total & 283 & 543 & 1865 & $2691+$ \\
\hline 5 first day & 66 & 125 & $537 * * *$ & 728 \\
\hline 5 second day & 84 & 146 & 361 *** & 591 \\
\hline \multicolumn{5}{|l|}{ I first day, } \\
\hline 4 second day & 66 & 146 & $425 * *$ & 637 \\
\hline \multicolumn{5}{|l|}{4 first day, } \\
\hline I second day & 67 & 126 & $544 * *$ & 737 \\
\hline Total & 283 & 543 & 1867 & 2693 \\
\hline
\end{tabular}

t Two flowers visits were excluded from the upper portion of the table because the age of the visited flowers was not recorded.

\section{References}

DOBSON, H E M (|99|) Pollen and flower fragrances in pollination. Acta Horticulturae. 288: 313-320.

KEMP, J R (1994) Floral Morphology and Pollination Biology of Rosa setigera Michaux. Doctoral dissertation, University of Guelph.

KEVAN, P G; EISIKOWITCH, D; AMBROSE, J D; KEMP, J R (1990) Cryptic dioecy and insect pollination in Rosa setigera Michx. (Rosaceae), a rare plant of Carolinian Canada. Biological Journal of the Linnean Society. 40: 229-243.

MENZEL, R; ERBER, J (1978) Learning and memory in bees. Scientific American. 239: 80-88.

PROCTOR, M; YEO, P; LACK, A (1996) The Natural History of Pollination. Timber Press, Inc., Portland, Oregon, 479 pp. 